\title{
Nursing study abroad trip preparation: finding consensus through a Delphi technique.
}

LEAR, $\mathrm{H}$.

2020 


\section{Journal Pre-proof}

Nursing study abroad trip preparation: Finding consensus through a Delphi technique

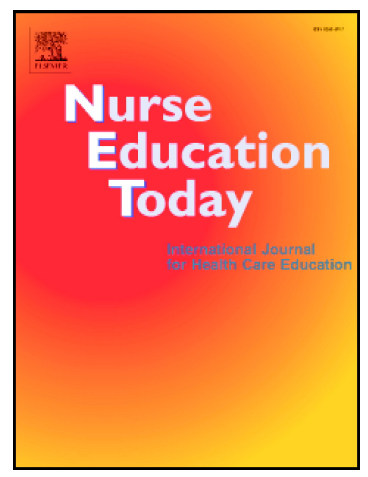

Holly Lear

PII: $\quad$ S0260-6917(19)31420-0

DOI: $\quad$ https://doi.org/10.1016/j.nedt.2020.104443

Reference: $\quad$ YNEDT 104443

To appear in: $\quad$ Nurse Education Today

Received date: $\quad 20$ September 2019

Revised date: $\quad 11$ February 2020

Accepted date: $\quad 14$ April 2020

Please cite this article as: H. Lear, Nursing study abroad trip preparation: Finding consensus through a Delphi technique, Nurse Education Today (2018), https://doi.org/ 10.1016/j.nedt.2020.104443

This is a PDF file of an article that has undergone enhancements after acceptance, such as the addition of a cover page and metadata, and formatting for readability, but it is not yet the definitive version of record. This version will undergo additional copyediting, typesetting and review before it is published in its final form, but we are providing this version to give early visibility of the article. Please note that, during the production process, errors may be discovered which could affect the content, and all legal disclaimers that apply to the journal pertain.

(C) 2018 Published by Elsevier. 


\title{
NURSING STUDY ABROAD TRIP PREPARATION: FINDING CONSENSUS THROUGH A DELPHI TECHNIQUE
}

\author{
Holly Lear, PhD MPH RN \\ PhD Student \\ Robert Gordon University \\ Aberdeen, United Kingdom
}

1911 Hannah Jo Ct

Iowa City, Iowa 52240

holly.lear@kirkwood.edu

417-860-8974

\section{Funding Source}

This research did not receive any specific grant from funding agencies in the public, commercial, or not-for-profit sectors.

\section{Conflict of Interest}

None declared

\section{Ethical Approval}

Robert Gordon University's School of Nursing and Midwifery ethics

committee approved the research in this paper which was part of a doctoral study 


\section{INTRODUCTION}

Nursing study abroad trips are rising in popularity (Open Doors, 2017; Crump et al., 2010). Nursing students may travel the globe studying abroad, sometimes to locations where the culture, language, and healthcare practices are very different to what the students are used to. Study abroad trips are justified by Higher Educational Institutions (HEIs) as learning opportunities that increase students' cultural competence (Kohlbry and Daugherty, 2015; Westerbotn et al., 2015; Gower et al., 2018). Responding to an increasingly diverse patient population, study abroad trips provide students with a chance to learn about a culture different from their own to provide culturally appropriate care upon becoming newly qualified nurses.

The three stake holder groups to consider are the students, the receiving institution, and the sending institution. Each group has a role to play in ensuring a successful study abroad trip that is safe to all parties, and educational for the students. An important consideration is the presence of students entering unknown contexts where risk abounds. Medical emergencies of any sort may occur, potentially in a rural location without access to medical care or where communication is impossible due to language barriers or lack of internet access. External risks present another set of possibilities for which to prepare, such as the threat of violence, political unrest, and communicable diseases.

Without a definition of preparation, harm to students or patients abroad pose heightened legal implications - particularly for sending institutions. The absence of preparation, inconsistent learning objectives, and lack of benefits for the hosting institution have led some to criticise study abroad trips as post-colonial voyeurism (Anderson et al., 2003; Racine and Perron, 2012. The fact remains that such trips have little scrutiny, with the focus not on the population receiving care at the study abroad trip site - but on the learning opportunities for the students.

A definition of preparation was required that could guide nursing Higher Education Institutions (HEIs) to inform best practice for nursing study abroad trips. Due to the 
depth and scope of the preparation needed for nursing study abroad trips, it was challenging to identify a definition of 'preparation' and subsequently 'preparedness' (the degree to which the aspects of preparation were realised).

\section{LITERATURE}

The researcher undertook a literature review systematically on the subject of preparation in nursing study abroad trips. While this paper does not follow a literature review method exactly, it is guided by the principles of an integrative method (Cooper, 1998). An integrative literature review method follows a comprehensive approach, allows for a diversity of methodologies, includes theoretical as well as experimental research, and is able to define concepts (Broome, 2000). Beginning with the identification of a problem, a literature search, data evaluation, data analysis, and finally a presentation, this review addresses the gap in the literature of how nursing students prepare for nursing study abroad trips.

Of the 214 articles collected on nursing study abroad trips, 30 of them (14\%) discussed preparation using one sentence or more. No clear definition of preparation was found, and most articles that mentioned preparation did so briefly (Farmer et al., 2003; Goldberg and Brancato, 1998; De Natale and Waltz, 2015; Shailer, 1997; Folse, et al. 2015; Read, 2011; Egenes, 2012). Even within collaborative consortiums, no two preparation modules were found to be the same (Koskinen and Jokinen, 2007; Duffy et al., 2005).

To provide an example of the widely varying preparation styles, consider the following. At one sending institution, a required preparation course covered the culture of the study aboard host location (Farmer et al., 2003). At another sending institution, a course taught applied research strategies, global health/health disparities, the culture and values of the host country, and students were expected to report daily activities (Anderson et al., 2012). Language courses were recommended at another institution, however the language courses were not always offered at the appropriate semester before students would study abroad, complicating students' ability to prepare linguistically (Critchley et al., 2009). 
The few articles that mentioned preparation mostly kept details to one sentence. Gower et al. stated their nursing students' preparatory sessions included host country culture, clinical practice, safety, and a daily itinerary (Gower et al., 2017). Another group of nursing students took a transcultural nursing course that including assignments, group work underpinned by Purnell's (2005) Model of Cultural Competence, and preparing health talks (Brown, 2017). An article that provided more information than usual regarding preparation still reported that students felt 'somewhat underprepared' regarding culture and clinical responsibilities during their study abroad trip (Halcomb et al., 2018).

It is expected, then, that if the nursing literature reports underprepared students enrolled in study abroad trips, and $86 \%$ of articles do not mention preparation at all, then the problem of underprepared students is larger than previously thought. According to the literature, a group of students reportedly made mistakes while studying abroad (Wros and Archer, 2010). Another sending HEI began preparing students six months before the trip, but a student from this institution enrolled to study abroad just four days prior to studying abroad, and reported crying the entirety of the first day abroad, saying 'it was so horrible' (Pross, 2005 p. 630). The other students that had six months of preparation still experienced fearfulness and hearing gunshots, which made them anxious. Another group of students expressed difficulty anticipating their preparation needs, not knowing certain details of the trip until immediately before departure (Critchley et al., 2009).

In any discussion of preparation, the potential for harm ought to be considered. Study abroad trips can induce feelings of discomfort in students, arguably aiding in the education process. Greatrex-White (2008) discusses how study abroad trips trigger a 'positive disturbance', able to expose racism, beliefs, and assumptions. Others identify stressors students may experience abroad as a time ripe for learning (Lear et al., 2018), referring to the phenomenon as constructive disequilibrium (Che et al., 2010). However, feelings of discomfort can quickly become more serious while studying abroad, as difficult living conditions, lack of 
resources, dangerous environments, the desire to make a positive impact with limited time, and trying to replicate practices from one's home country can induce culture shock (Chisholm and Pettigrew, 2012). The number of students who reported culture shock in the literature is high (Kent-Wilkinson et al., 2010; Egenes, 2012, Heuer et al., 1997; Button et al., 2005; Duffy et al., 2005; Caldwell and Purtzer, 2015; Arthur, 2001) (this is by no means an exhaustive list). Beyond culture shock, risks span physical, clinical-professional, and sociocultural harm (Bell, 2014). Unforeseen risks may include accidents, political unrest, ill health due to climate, psychological disorders, and assault (Morgan, 2012).

The review of the literature supports the need for an accepted definition, and standardisation and consistency of preparation for nursing study abroad trips. Study abroad coordinators are concerned, after decades of sending students abroad, how best to prepare students prior to their study abroad trips (Johns and Thompson, 2010). Researchers are calling for a critical examination of current practice, development of evidence-based practice (Browne et al., 2015), and for better-prepared students and volunteers (Crisp 2007; All-Party Parliamentary Group, 2013).

\section{Working definition of preparation}

Informed by the literature review, the researcher composed a working definition of what preparation could encompass. Seven components will be validated in the Delphi. The definition of preparation is as follows:

a) Acquisition of practical information, i.e. vaccinations, what to bring (Institute for the International Education of Students, 2008);

b) Development of clinical skills, especially those related to prevalent diseases in the host location that may be uncommon in the student's country of residence (Mill et al., 2005);

c) Development of managerial skills, or the ability to overcome a lack of resources with innovation as well as the ability to identify points of improvement while abroad (NHS, 2010); 
d) Development of communication skills, or the ability to work in a multidisciplinary team across cultures (Department of Health, Department for International Development 2014)

e) Development of cultural skills, or gaining understanding of cultural practices in the host location to best provide care within the patient's culture, providing dignity (Leininger, 1996)

f) Development of emotional skills, or the ability to recognise and articulate feelings (Koskinen et al., 2009; Riner, 2011; Davis et al., 2015)

g) Creation of a mission statement (Currier et al., 2000) on the part of the sending institution denoting the goals of the trip; a needs statement from the receiving institution stating what needs to be done along with an invitation to come (Crisp, 2007); a learning contract on the part of the student as supported by Joplin's theory of Experiential Education (1981).

\section{METHOD}

The aim and objective of this study was to define and gain consensus on the definition of preparation for nursing study abroad trips. A Delphi consensus research method was chosen to validate and add rigour to a working definition of preparation. The Delphi study is justified through firstly, allowing experts to access the questionnaire regardless of their geographical location (Diamond et al., 2014), and secondly, to enhance the existing body of knowledge due to the lack of agreement of empirical evidence informing the process of preparation and preparedness for nursing study abroad trips. This Delphi method is modified due to the literature review generating sufficient evidence that it replaced the purpose of the usual first round. Therefore, the first round of the Delphi immediately asks experts to rank their opinions.

\section{Delphi technique}

A Delphi is a consensus method, wherein each expert is able to contribute individually to a group communication process through a series of rounds. 
Originating in 1951 at the RAND Corporation (Dalkey and Olaf), opinions are cast by experts, then analysed for degree of consensus. Analysed opinions are fed back to the experts anonymously, then experts may alter their consensus after further reflection of the expert panel's response in subsequent rounds. When experts reach a minimum agreement consensus level of 75\% (van Houwelingen et al., 2016), the Delphi study is complete. An alternative such as the content validity index is also suitable for confirming agreement (Polit and Beck, 2006). If consensus is not reached, the next round ensues.

\section{Pilot of Delphi study}

The Delphi was piloted to ensure the questions were clear and posed no technical difficulties. The pilot findings showed that $91 \%$ of questions reached consensus among the panel of experts. One question was added to the beginning of the questionnaire, which asked for the location(s) where experts had experience with study abroad trips. This was in preparation to cross-tabulate location with level of preparedness, as the researcher would examine location's effect on an expert's answers. Due to the feedback concerning the question about managerial skills, the term was redefined to 'a nursing student's ability to work autonomously, managing his or her own workload while abroad'.

Figure 1 displays that $70 \%(n=7)$ of experts in the pilot felt nursing students were somewhat prepared to study abroad. Two experts felt students were adequately prepared, and one expert felt students were inadequately prepared.

\section{Ethical considerations}

Ethical approval was received from the researcher's School of Nursing and Midwifery to conduct this study. Nominated experts (see Selection of participants, below) were invited to join the study via email. Experts were informed they could leave the study at any time and that their completion of the Delphi questionnaire signified their consent for their quotes to be anonymised and used in the wider study and future publications. Experts were sent one reminder email per round. 


\section{Sampling strategy}

A Delphi study requires 'expert' purposive sampling because it would not be appropriate to ask a randomised sample of the general nursing population questions which are specific only to those with expertise and involvement in nursing study abroad trips (Skulmoski et al., 2007). Thus, expert purposive sampling was chosen for respondents to represent experts in the field of nursing study abroad trips (Ruemler, 2016). Respondents are referred to in this chapter as 'experts'.

The requirements for an expert in this Delphi study included involvement with study abroad trips. A diverse group of individuals from different backgrounds included but was not exclusive of study abroad coordinators, faculty members, students, and receiving institution coordinators responsible for supporting students while abroad. Diversity of expert experience was suggested to ensure a robust definition of preparation (Parratt et al., 2016). Experts were asked in the first questions of the Delphi to share how long they had been involved in study abroad trips, and countries they had involvement or responsibility.

\section{Selection of participants}

Sandrey and Bulger (2008) suggest that a sample size of 5-10 per group is adequate in a heterogeneous sample. The three groups desired in this sample of the students, receiving institutions, and sending institutions equalled a target of 1530 sample size following Sandrey and Bulger's suggestion. Some researchers have used as little as 3 experts per group in a heterogeneous sample (Kirschbaum et al., 2019). To achieve this sample size, snowball sampling was used (van Houwelingen et al., 2016). Snowball sampling consisted of experts being asked to nominate other experts in the field in order to broaden the size and scope of the research study. The researcher asked persons responsible for overseeing study abroad trips at her university to nominate experts in the field. The sampling technique was widened to include two additional groups: Higher Education Statistics Agency Limited (HESA); a not-for-profit company in the United Kingdom that provides statistical data concerning study abroad trips, and the researcher's colleagues from past experiences studying abroad. HESA contributed the top ten universities that 
reported participation in nursing study abroad trips. A limitation arose that not all universities reported data to HESA, meaning universities not present in HESA's database may have had key experts who were not included in this study. These universities were contacted and asked for nominations of experts who fit the criteria of the Delphi study. An invitation was sent via email to all nominated persons for inclusion in the Delphi's expert panel.

\section{Instrument}

An original survey instrument sourced demographic information from experts along with questions regarding responsibility related to study abroad trips. The working definition of preparation (above) was turned into questions wherein experts ranked their agreement with each component. The use of a working definition replaced the classic first round of a Delphi, which is used to generate ideas. This allowed the experts to begin ranking their agreement in a streamlined, efficient manner. In addition to the working definition, themes from the literature were included, allowing the researcher to ask the panel of experts their stance on differing styles of preparation seen in the literature. These questions were separated according to responsibility, i.e. whether the student, sending HEI, or receiving HEI was responsible for the component of preparation. For example, experts were asked to rank their agreement with the statement, 'nursing students should be responsible for their own preparation to study abroad', because this was a theme in the literature review (Doyle, 2004). In the final question, experts were invited to add a new aspect if they felt the definition was incomplete (West et al., 2015). When similar statements were repeated, the similar statements were condensed into one (see Round 1 Results). The statements experts contributed were disseminated back to the panel of experts in the subsequent round to measure consensus.

\section{Analysis}

The Delphi rounds were analysed using mixed methods. Analysis of Likert scale questions, consensus, and descriptive data analysis using SPSS was identical to the methods discussed in the pilot (see Pilot of Delphi Study). Most questions were Likert five-point scale questions, analysed with statistical measurements of central 
tendency (including mean, median, and mode) and level of dispersion (standard deviation and interquartile range) (Hsu and Sandford, 2007) (see Table 1 for mean and standard deviation). The final question which allowed experts to submit qualitative data was analysed by condensing similar statements into one statement and disseminated back to the panel of experts in the subsequent round to measure consensus.

\section{DATA COLLECTION}

The Delphi method was modified due to the classic first round of generating ideas being replaced by a literature review and data gathered from the pilot. Data collection began by creating an online survey through the software Snap Surveys. A hyperlink was sent via email to access the survey, providing a structured, timelimited format, although the survey remained open in the first round until a desired sample size was reached. One reminder email was sent after two weeks.

\section{Delphi round 1}

The first round of the Delphi immediately sought experts to rank their opinions as ideas had already been generated from the literature review.

A completion date was not given for the first round because experts were still being recruited via snowball sampling. Snowball sampling led to the inclusion of experts from multiple countries, creating rich perspective from each of the desired groups (students, receiving institutions, and sending institutions). The first round of the survey remained open for five weeks until a suitable sample size of 23 was obtained.

\section{Round 1 results}

In the first round, a total of 37 experts were identified and invited to take part in the study, with 23 completed responses. Figures 2 and 3 describe the experts who agreed to take part in the Delphi. The largest group $(57 \%, n=13)$ of experts defined themselves as 'professor/lecturers involved with study abroad trips'. The smallest group represented among the experts was management overseeing study abroad trips $(9 \%, n=2)$. In terms of length of experience, the largest group ( $37 \%$ 
$\mathrm{n}=9$ ) reported having 6-10 years of experience with study abroad trips. Involvement was widespread around the world, representing expertise that spanned Europe, North and South America, Africa, and Asia (see Figure 3, keeping in mind experts may have reported involvement in more than one location). Descriptive data analysis was undertaken using SPSS version 21.

The Delphi utilised a ranking system via level of agreement in the definition of preparation. A 5-point Likert scale was used, which allowed the researcher to analyse each question to find out whether it had reached consensus of $75 \%$.

Most (84\%) of the Delphi questions reached consensus (defined as selecting 'agree' or 'strongly agree'; or similarly, 'disagree' or 'strongly disagree') of $75 \%$ or more (West et al., 2015; Diamond et al., 2014; Foth et al., 2016). The questions that did not reach consensus were included in the second round of the Delphi survey, so experts could see the group's answers as discussed in Figures 4-9. Less than half $(48 \%)$ of experts felt nursing students were adequately prepared to study abroad, and the remainder chose between 'somewhat' and 'inadequately' prepared (Figure 4). Cross tabulation revealed that the two experts who reported that students were inadequately prepared to study abroad were both responsible for sending students abroad. However, this did not reflect the views of other members in the group. The most optimistic group of experts about student preparation were those responsible for sending students abroad (58\%). Similarly, $71 \%$ of receiving coordinators felt students were adquately prepared. In terms of experience, half of the most experienced group of experts (with 11 or more years experience) reported students were only 'somewhat prepared' to study abroad. All remaining groups felt students were 'somewhat prepared' or 'inadequately prepared' more frequently than 'adequately' prepared. Figure 5 shows how prepared experts felt students were to study abroad according to their country of experience. A wide range of countries are represented in the 'adequately prepared' section of Figure 5 , and thus location was unremarkable. Figures 6-8 illustrate the questions that did not reach consensus. 
The last question of Round 1 invited experts to offer suggestions they felt should be added to the definition of preparation. Delphi studies typically do not specify the type of qualitative analysis used beyond referring to content analysis and reporting that common themes were grouped (Keeney et al., 2006; Jacob et al., 2017). Common themes arose in two suggested components for the definition that were grouped and made into new statements, decreasing repetitiveness. The qualitative statements offered by experts are available in Figure 9. Statements showing more than one response represent repeated ideas that were grouped into one statement. The new statements that were suggested in the first round were added to the second round of the Delphi.

\section{Delphi round 2}

In the second round, questions that did not reach consensus were asked again, this time following a graph of responses from the first round. This gave opportunity for experts to answer the questions again in light of the rest of the panel's responses. For brevity and due to 13 of the 24 questions having $100 \%$ agreement among experts, questions that reached consensus were not asked a second time.

The second round of Delphi questions were sent to all Delphi experts, including those that missed the cut off date for the first round. This did not pose a limitation because all experts invited to be in the study represented a panel of heterogeneous expertise. Further, no correlations were drawn between individual responses changing in subsequent rounds. Therefore all experts received invitations to each Delphi round.

Similarly, expert attrition was expected throughout each subsequent Delphi round (West et al., 2015; Parratt et al., 2016; van Houwelingen, et al., 2016) posing a possibility for change in the expert panel. Attrition occurred in part because the second round of the Delphi study coincided with summer holidays for many of the experts. The second round remained open for five weeks, longer than expected, to achieve 20 responses ( $87 \%$ response of the first round). 


\section{Round 2 results}

The Delphi reached consensus in the second round. A shift occurred in how experts felt nursing students were prepared to study abroad (Figure 10) from the first round of the Delphi. The bias of social desirability may have contributed to the shift. It is unlikely that an expert involved with study abroad trips would immediately choose a pessimistic view of how prepared their students are to study abroad. On the contrary, they would be wise to affirm the students were prepared. Further, while no experts chose 'not prepared at all' in the first round, $10 \%$ of experts selected this choice in the second round. The rise in 'somewhat prepared' in the second round is interpreted as a true representation of the perceptions of the experts as to the preparedness of students. This is evidenced by nearly half ( $48 \%$ ) of the experts reporting students were 'adequately prepared' in the first round, to the majority (70\%) selecting 'somewhat prepared' in the second round. Figure 11 shows the results of the only question that did not reach consensus.

\section{$\underline{\text { Results }}$}

The panel of experts achieved a minimum consensus of $75 \%$ on a definition in the second round. The new and validated definition of preparation was separated to allocate responsibilities to relevant parties and specifies content that should be included. The revised definition based on the findings is below.

\section{Definition of preparation}

Nursing students preparing to study abroad must...

1. Be told what to bring on their study abroad trip

2. Create a learning contract including educational expectations of the trip

3. Familiarise themselves with clinical skills related to prevalent diseases in the host location

4. Acquire country specific knowledge such as culture, history, religion, economy and healthcare 
5. Identify ways of improving the study abroad experience for future students

6. Acquire communication skills necessary to work in a multi-disciplinary team

7. Provide care respecting the cultural practices in the host location

8. Learn common phrases to communicate basic needs if they are unfamiliar with the host country language

9. Understand the underlying public health issues (such as contaminated water, poverty, or poor hygiene) that affect a community

10. Possess or acquire the reflective skills to appreciate the learning gained from studying abroad

11. Anticipate what they will see, hear, smell and encounter that is different from their home country

12. Expect unforeseen circumstances to arise, requiring an attitude of flexibility/resilience

13. Understand they will not be $100 \%$ prepared

Receiving institutions must...

14. Confirm the students are welcome to undertake a study abroad trip to their institution

15. Ensure that the roles and responsibilities allocated to students are aligned to specific needs of the local population

16. Provide appropriate preparation and orientation to students once they arrive to their study abroad location

Sending institutions must...

17. Be responsible to prepare nursing students to study abroad, including a delineation of approved scope of practice

18. Create a mission statement denoting the goals of the trip

19. Dedicate a supporting coordinator responsible for the students to handle emergencies if they arise

20. Facilitate debriefing with nursing students when the study abroad trip is complete, including ethical response to significant events (i.e. malpractice) 
Preparation training for nursing students to study abroad should include...

21. Acquisition of practical information

22. Training that is focused on the study abroad trip and the students' future career as a nurse

23. Development of managerial skills, or the ability to manage responsibilities with autonomy

24. Development of communication skills, or the ability to interact with a multidisciplinary team in the host location

25. Development of cultural skills, or gaining understanding of cultural practices in the host location to best provide care within the patient's culture

26. Time to reflect on the emotional reactions students may experience while abroad

27. Preparation for the return home with opportunity to debrief about their experiences whilst on the trip

\section{DISCUSSION}

The question of how nursing students are prepared to study abroad was investigated. The literature showed preparation to be an underreported topic. The researcher posits that the lack of discussion of preparation in the literature is suggestive of a largely underprepared study abroad culture in the majority of institutions. Further, it is possible that more nursing students feel underprepared than what is seen in the literature due to fear of the sending institution receiving a poor reputation or having legal ramifications when study abroad trips cause harm.

A noteworthy shift in expert reporting occurred in the second round of the Delphi. Experts chose more pessimistic ratings for the level which nursing students were prepared to study abroad. The researcher attributes the change to the experts reading the specific ways a student ought to be prepared according to various literature. Therefore it is possible that the experts began to feel that students were not so prepared after all. The researcher suggests that the experts were ready, upon receiving the second round of the Delphi, to report that in fact their students were less prepared than previously reported. 
This study is the first to produce a new and validated definition of nursing study abroad preparation. The new definition allocated responsibilities to nursing students, receiving institutions, and sending institutions. Preparation training content was the final component of the new definition, offering subjects to cover for nursing students prior to studying abroad.

\section{CONCLUSION}

A Delphi consensus research method was chosen to validate and add rigour to a working definition of preparation. In the Delphi pilot, $70 \%$ of experts felt nursing students were somewhat prepared to study abroad. Changes following the pilot included a new question that inquired as to the location of experience experts had in the field of nursing study abroad trips. Following the pilot, experts were recruited using snowball sampling to achieve a purposive expert sample. Experts were emailed a hyperlink to take part in the study, and after providing demographic data, ranked their agreement with the components of the working definition of preparation using a 5-point Likert scale, and recommended additional components if desired. The expert panel consisted of the three desired groups: students, receiving institutions, and receiving institutions; among other relevant groups with required study abroad involvement. Of the 37 experts who were invited to join the Delphi, 23 completed the first round. Components of the definition were largely supported by the experts, with $84 \%$ of the questions reaching consensus in the first round. In the second round of the Delphi, 20 experts responded. Feelings shifted regarding the preparedness of nursing students prior to studying abroad, with experts changing their answers in the second round to options denoting students were less prepared. Consensus was reached in the second round, completing the Delphi study and producing a validated definition of preparation. The Delphi was completed in the second round after achieving a minimum consensus of $75 \%$ on a definition.

Limitations of this study include the difficulty of implementation. Established study abroad programs which have no emergencies or harm occur abroad have little 
reason to alter their methods. The adoption of better preparation then relies on a duty to follow best practice for the purpose of providing nursing students with highquality education. Further, to deliver dignified, high-quality care in international contexts so not to exploit or cause harm from cultural misunderstandings and lack of understanding of local illnesses. Another limitation of this research is the possibility that preparation is conducted more often than is reported in the literature.

The new and validated definition presented in this article is intended to guide best practice for future study abroad trips. Study abroad coordinators are encouraged to consider the content of their existing preparation courses and add components of the definition of preparation that are lacking in their preparation programmes. 


\section{REFERENCES}

All-Party Parliamentary Group, 2013. Improving health at home and abroad. APPG, London.

Anderson, J., Perry, J., Blue, C., Browne, A., Henderson, A., Khan, K.B., Kirkham, S.R., Lynam, J., Semeniuk, P., Smye, V., 2003. 'Rewriting' cultural safety within the postcolonial and postnational feminist project: Toward new epistemologies of healing. Advances in Nursing Science 26 (3), 196-214.

Anderson, K.H., Friedemann, M., Büscher, A., Sansoni, J. and Hodnicki, D., 2012. Immersion research education: Students as catalysts in international collaboration research. International Nursing Review 59 (4), 502-510.

Arthur, N., 2001. Using critical incidents to investigate cross-cultural transitions. International Journal of Intercultural Relations 25 (1), 41- 53.

Bell, H., 2014. Becoming a successful student in pre-registration nurse education: A qualitative multiple case study, PhD Diss., University of East Anglia.

Brown, C.L., 2017. Linking public health nursing competencies and service- learning in a global setting. Public Health Nursing 34 (5), 485-492.

Broome, M.E., 2000. Integrative literature reviews for the development of concepts. Concept development in nursing: Foundations, techniques and applications. Philadelphia: WB Saunders Company, 231-250.

Browne, C.A., Fetherston, C.M. and Medigovich, K., 2015. International clinical placements for Australian undergraduate nursing students: A systematic thematic synthesis of the literature. Nurse Education Today 35 (10), 1028-1036.

Button, L., Green, B., Tengnah, C., Johansson, I., Baker, C., 2005. The impact of international placements on nurses' personal and professional lives: Literature review. Journal of Advanced Nursing 50 (3), 315-324.

Caldwell, P., Purtzer, M.A., 2015. Long-term learning in a short-term study abroad program: 'Are we really truly helping the community?'. Public Health Nursing 32 (5), 577-583.

Che, S., Spearman, M., Manizade, A., 2010. Constructive disequilibrium. In: R. Lewin, ed, The handbook of practice and research in study abroad: Higher Education and the Quest for Global Citizenship. Routledge, 99-116.

Chisholm, G., Pettigrew, L., 2012, The volunteer journey: Potential benefits, barriers, challenges and solutions, viewed 8 December 2014, <http://www.thet.org/volunteer-poster>. 
Cooper, H.M., 1998. Synthesizing research: A guide for literature reviews. 2, Sage.

Crisp, N., 2007. Global Health Partnerships: The UK contribution to health in developing countries. Public Policy and Administration 23 (2), 207-213.

Critchley, K.A., Richardson, E., Aarts, C., Campbell, B., Hemmingway, A., Koskinen, L., Mitchell, M.P., Nordstrom, P., 2009. Student experiences with an international public health exchange project. Nurse Educator 34 (2), pp. 69-74.

Crump, J.A., Sugarman, J. and Working Group On Ethics Guidelines For Global Health Training (WEIGHT), 2010. Ethics and best practice guidelines for training experiences in global health. The American Journal of Tropical Medicine and Hygiene 83 (6), 1178-1182.

Currier, C., Omar, M., Talarczyk, G., Guerrero, R.D., 2000. Development and implementation of a semester program in Mexico for senior nursing students. Journal of Professional Nursing, 16 (5), 293-299.

Davis, L.I., Wright, D.J., Gutierrez, M.S., Nam, J.J., Nguyen, J., Waite, A.T., 2015. Interprofessional global service learning: A pharmacy and nursing practice experience in Botswana. Currents in Pharmacy Teaching and Learning 7 (2), 169178.

De Natale, M.L., Waltz, C.L., 2015. Reflections of nursing students travel abroad experiences in Ireland: A global nursing perspective. Nursing Education Perspectives 36 (3), 188-189.

Department of Health and Department For International Development, 2014. Engaging in global health: The framework for voluntary engagement in global health by the UK health sector. www.gov.uk/dh.

Diamond, I.R., Grant, R.C., Feldman, B.M., Pencharz, P.B., Ling, S.C., Moore, A.M., Wales, P.W., 2014. Defining consensus: A systematic review recommends methodologic criteria for reporting of Delphi studies. Journal of Clinical Epidemiology 67 (4), 401-409.

Doyle, R.M., 2004. Applying new science leadership theory in planning an international nursing student practice experience in Nepal. The Journal of Nursing Education 43 (9), 426-429.

Duffy, M., Farmer, S., Ravert, P., Huittinen, L., 2005. International community health networking project: Two year follow- up of graduates. International Nursing Review 52 (1), 24-31.

Egenes, K.J., 2012. Health care delivery through a different lens: The lived experience of culture shock while participating in an international educational program. Nurse Education Today 32 (7), 760-764. 
Farmer, S., Raver, P., Huittinen, L., 2003. Institutional issues in the implementation of an international student exchange program. Journal of Nursing Education 42 (9), 399.

Folse, V.N., Jarvis, C.M., Swanlund, S.L., Timan, M.R., 2015. The creation of a synchronous learning environment to support a study abroad program for nursing majors at a traditional liberal arts university. Journal of Professional Nursing 31 (3), 233-241.

Foth, T., Efstathiou, N., Vanderspank-Wright, B., Ufholz, L., Dütthorn, N., Zimansky, M., Humphrey-Murto, S., 2016. The use of Delphi and Nominal Group Technique in nursing education: A review. International Journal of Nursing Studies $60,112-120$.

Goldberg, L.K., Brancato, V.C., 1998. International education: A United Kingdom nursing student partnership. Nurse Educator 23 (5), 30-34.

Gower, S., Dantas, J.A., Duggan, R., Boldy, D., 2018. The influence of international nursing placements on cultural competence and career planning. Australian Nursing and Midwifery Journal 26 (1), 41-41.

Gower, S., Duggan, R., Dantas, J.A., Boldy, D., 2017. Something has shifted: Nursing students' global perspective following international clinical placements. Journal of Advanced Nursing 73 (10), 2395-2406.

Greatrex-White, S., 2008. Uncovering study abroad: Foreignness and its relevance to nurse education and cultural competence. Nurse Education Today 28 (5), 530538.

Halcomb, E., Antoniou, C., Middleton, R., Mackay, M., 2018. The experiences of Australian undergraduate nursing students of a clinical placement in Cambodia. Collegian 25 (3), 313-318.

Heuer, L., Russell, L., Kahlstorf, H., 1997. Short-term cultural immersion in Russia. The Prairie Rose 66 (1), 7-11.

Hsu, C., Sandford, B.A., 2007. The Delphi technique: Making sense of consensus. Practical Assessment, Research \& Evaluation 12(10), 1-8.

Institute For The International Education Of Students, 2008. Last update, The IES abroad MAP for study abroad programs. Available:

https://www.iesabroad.org/export/sites/default/resources/pdf/Advisors_n_Faculty/I ES_MAP_BOOK.pdf [21 August, 2018].

Johns, A., Thompson, C.W., 2010. Developing cultural sensitivity through study abroad. Home Health Care Management \& Practice 22 (5), 344-348. 
Joplin, L., 1981. On defining experiential education. Journal of Experiential Education 4 (1), 17-20.

Kent-Wilkinson, A., Starr, L., Dumanski, S., Fleck, J., Lefebvre, A., Child, A., 2010. International nursing student exchange: Rural and remote clinical experiences in Australia. Journal of Agromedicine 15 (1), 58-65.

Kirschbaum, M., Barnett, T., Cross, M. (2019). Q sample construction: A novel approach incorporating a Delphi technique to explore opinions about codeine dependence. BMC Medical Research Methodology 19 (1), 101.

Kohlbry, P., Daugherty, J., 2015. International service-learning: An opportunity to engage in cultural competence. Journal of Professional Nursing 31 (3), 242-246.

Koskinen, L., Campbell, B., Aarts, C., Chassé, F., Hemingway, A., Juhansoo, T., Mitchell, M.P., Marquis, F.L., Critchley, K.A., Nordstrom, P.M., 2009. Enhancing cultural competence: Trans- Atlantic experiences of European and Canadian nursing students. International Journal of Nursing Practice 15 (6), 502-509.

Koskinen, L., Jokinen, P., 2007. Multicultural healthcare: A transatlantic project. Nurse Educator 32 (2), 89-93.

Lear, H., Eboh, W., Diack, L., 2018. A nurse researcher's guide to reflexive interviewing. Nurse Researcher 25 (4), 35-42.

Leininger, M., 1996. Culture care theory, research, and practice. Nursing Science Quarterly 9 (2), 71-78.

Mill, J.E., Yonge, O.J. and Cameron, B.L., 2005. Challenges and opportunities of international clinical practica. International Journal of Nursing Education Scholarship, 2(1).

Morgan, D.A., 2012. Student nurse perceptions of risk in relation to international placements: A phenomenological research study. Nurse Education Today 32 (8), 956-960.

NHS, 2010. The framework for NHS involvement in international development. Department of Health.

Norman, C., Dalkey, H.O., 1951. The use of experts for the estimation of bombing requirements - A project-Delphi experiment. The RAND Corporation; Santa Monica, CA.

Open Doors, 2017. Last update, Fast facts Open Doors 2017 [Homepage of Institute of International Education], [Online]. Available:

https://www.iie.org/Research-and-Insights/Open-Doors/Fact-Sheets-andInfographics/Fast-Facts [13 December, 2017]. 
Parratt, J.A., Fahy, K.M., Hutchinson, M., Lohmann, G., Hastie, C.R., Chaseling, M., O'brien, K., 2016. Expert validation of a teamwork assessment rubric: A modified Delphi study. Nurse Education Today 36, 77-85.

Polit, D.F., Beck, C.T., 2006. The content validity index: Are you sure you know what's being reported? Critique and recommendations. Research in Nursing \& Health. 29 (5), 489-97.

Pross, E., 2005. International nursing students: A phenomenological perspective. Nurse Education Today 25 (8), 627-633.

Purnell, L., 2005. The Purnell model for cultural competence. Journal of Multicultural Nursing \& Health $11(2), 7$.

Racine, L., Perron, A., 2012. Unmasking the predicament of cultural voyeurism: A postcolonial analysis of international nursing placements. Nursing Inquiry 19 (3), 190-201.

Read, C.Y., 2011. Semester abroad opportunities in baccalaureate nursing programs. Journal of Professional Nursing 27 (4), 221-226.

Riner, M.E., 2011. Globally engaged nursing education: An academic program framework. Nursing Outlook 59 (6), 308-317.

Ruemler, S.P., 2016. Analyzing the opinion of industry professionals on modelbased definition datasets to determine the most efficient method. Masters of Science edn. Purdue University.

Sandrey, M.A., Bulger, S.M., 2008. The Delphi method: An approach for facilitating evidence based practice in athletic training. Athletic Training Education Journal 3 (4), 135-142.

Shailer, B., 1997. Clinical electives: The challenges and benefits of student choice. British Journal of Nursing 6 (10), 575-583.

Skulmoski, G.J., Hartman, F.T., Krahn, J., 2007. The Delphi method for graduate research. Journal of Information Technology Education 6, 1.

Van Houwelingen, C.T., Moerman, A.H., Ettema, R.G., Kort, H.S., Ten Cate, O., 2016. Competencies required for nursing telehealth activities: A Delphi-study. Nurse Education Today 39, 50-62.

West, L.M., Diack, L., Cordina, M., Stewart, D., 2015. Applying the Delphi technique to define 'medication wastage'. European Journal of Hospital Pharmacy 22 (5), 274279. 
Westerbotn, M., Kneck, §, Hovland, O.J., Elrond, M., Pedersen, I., Lejonqvist, G., Dulavik, J., Ecklon, T., Nilsson, I. Sigurdardottir, ÁK., 2015. Taking part in Nordic collaboration; Nursing students' experiences and perceptions from a learning perspective: A qualitative study. Nurse Education Today 35 (5), 712-717.

Wros, P., Archer, S., 2010. Comparing learning outcomes of international and local community partnerships for undergraduate nursing students. Journal of Community Health Nursing 27 (4), 216-225. 
Credit Author Statement

I, Dr. Holly Lear, am the sole author of this paper. It was created during my doctoral studies as an original research project.

No conflict of interest declared 
Figure 1: In your experience, how prepared are nursing students to study abroad? Figure 2: Expert roles related to study abroad trips (Experts asked to tick all that applied)

Figure 3: Location of Expertise

Figure 4: In your experience, how prepared are nursing students to study abroad?

Figure 5: Student Preparation According to Location of Study Abroad Trip

Figure 6: Nursing students preparing to study abroad should be responsible for their own preparation to study abroad

Figure 7: Nursing students preparing to study abroad do not need an overarching aim of their trip

Figure 8: Preparation for nursing students to study abroad should include development of managerial skills, or the ability to manage responsibilities with autonomy

Figure 9: Please specify any further areas you believe nursing students should be prepared to study abroad

Figure 10: In your experience, how prepared are nursing students to study abroad?

Figure 11: Nursing students preparing to study abroad should be responsible for their own preparation to study abroad 
Table 1: Measures of Central Tendency

\begin{tabular}{|c|c|}
\hline Component of Definition & Mean (SD) \\
\hline How prepared & $1.61(0.66)$ \\
\hline Told what to bring & $1.48(0.73)$ \\
\hline Learning contract $\wedge$ & $1.41(0.59)$ \\
\hline Clinical skills & $1.48(0.59)$ \\
\hline Improving study abroad & $1.78(0.74)$ \\
\hline Communication skills & $1.44(0.51)$ \\
\hline Culture care & $1.22(0.42)$ \\
\hline Reflective skills $\wedge$ & $1.23(0.43)$ \\
\hline Overarching aim & $3.70(1.22)$ \\
\hline Do not need preparation & $4.61(1.03)$ \\
\hline Responsible for their own preparation & $3.04(1.52)$ \\
\hline Confirm students are welcome & $1.39(0.50)$ \\
\hline Roles and responsibilities & $1.30(0.47)$ \\
\hline Provide appropriate preparation & $1.26(0.45)$ \\
\hline Responsible to prepare & $1.30(0.47)$ \\
\hline Mission & $1.61(0.78)$ \\
\hline Supporting coordinator & $1.09(0.29)$ \\
\hline Facilitate debrief & $1.26(0.45)$ \\
\hline Practical info $^{\wedge}$ & $1.50(0.51)$ \\
\hline Teaching focused on future & $1.74(0.75)$ \\
\hline Develop clinical skills & $1.83(0.72)$ \\
\hline Develop managerial skills & $2.26(0.86)$ \\
\hline Communication skills $\wedge$ & $1.50(0.51$ \\
\hline Cultural skills $\wedge$ & $1.27(0.46)$ \\
\hline Time to reflect & $1.17(0.39)$ \\
\hline
\end{tabular}

$\wedge$ Denotes questions with one missing value; $n=22$ 


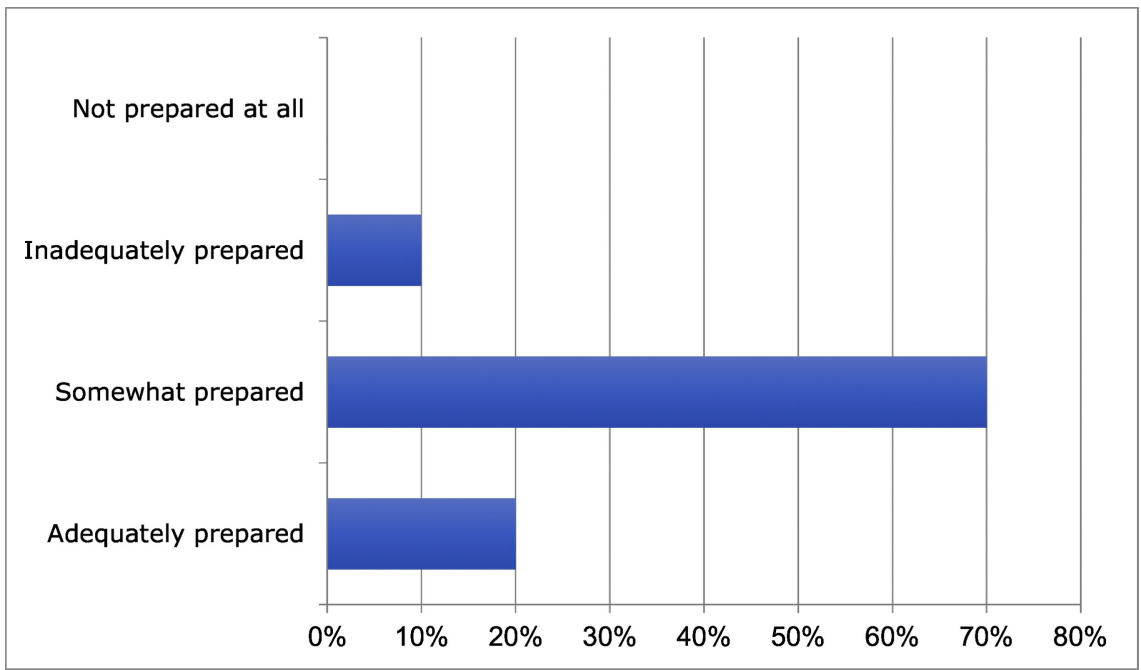

Figure 1 


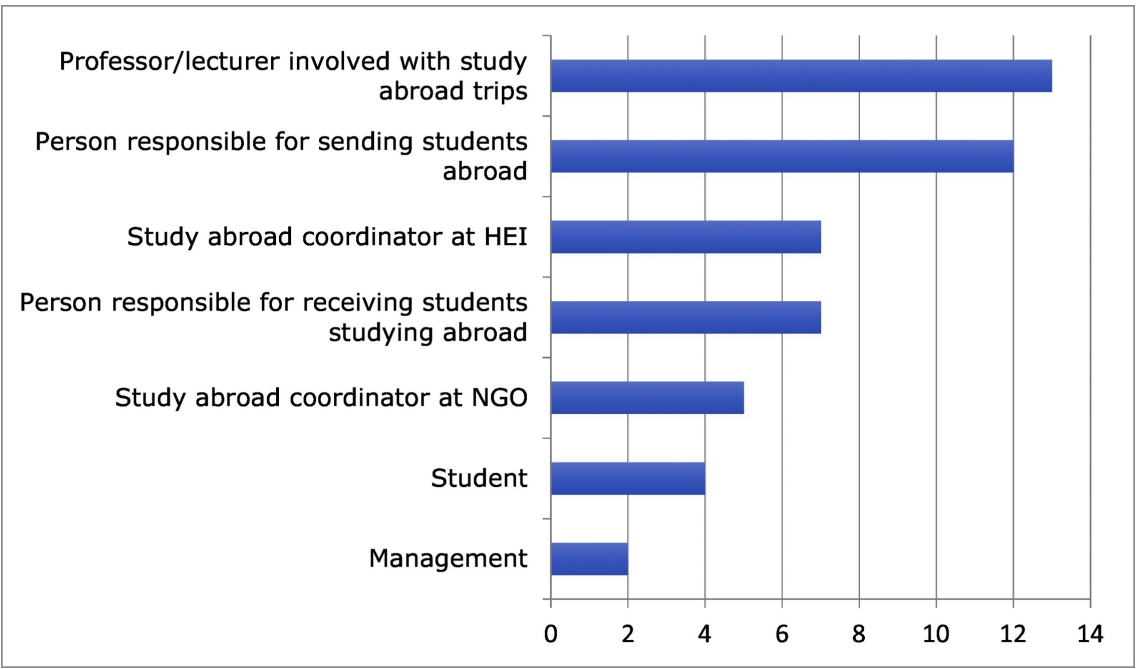

Figure 2 


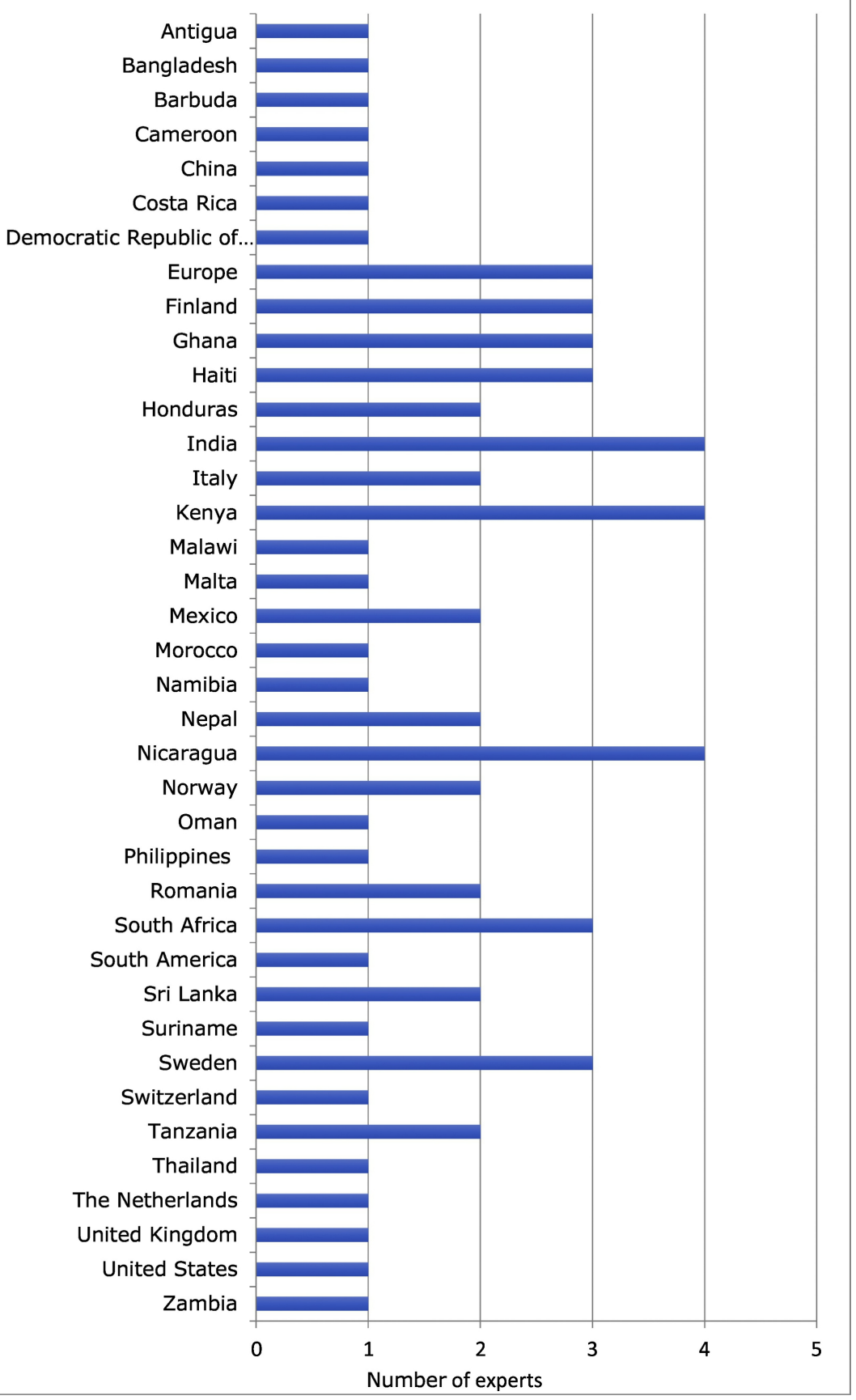

Figure 3 


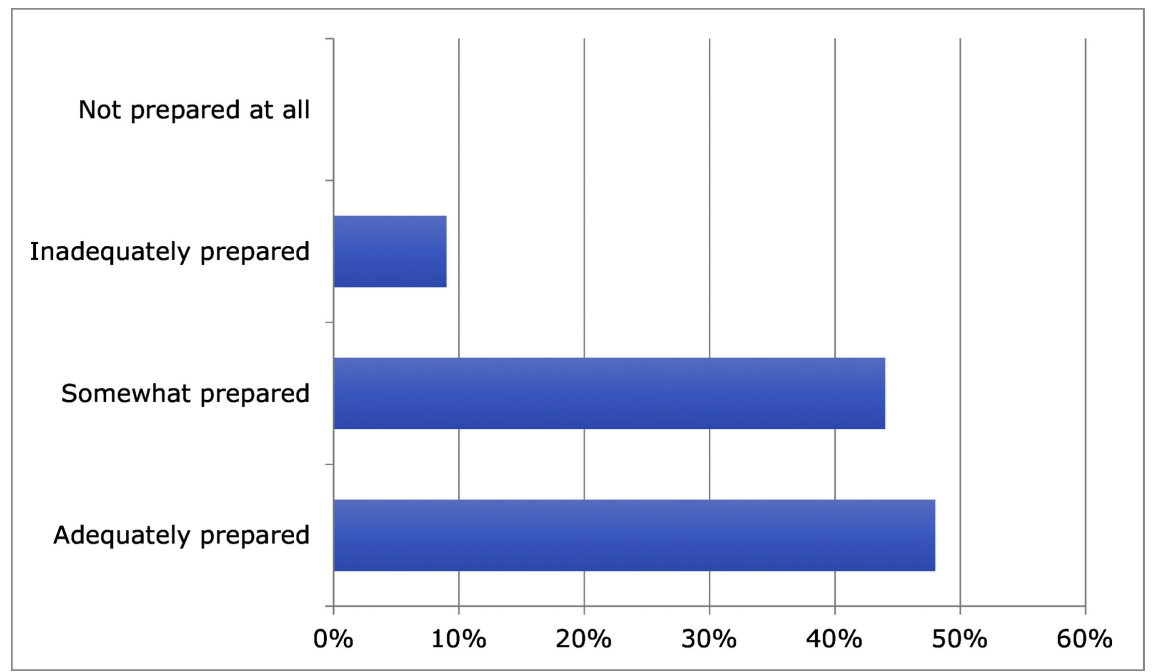

Figure 4 


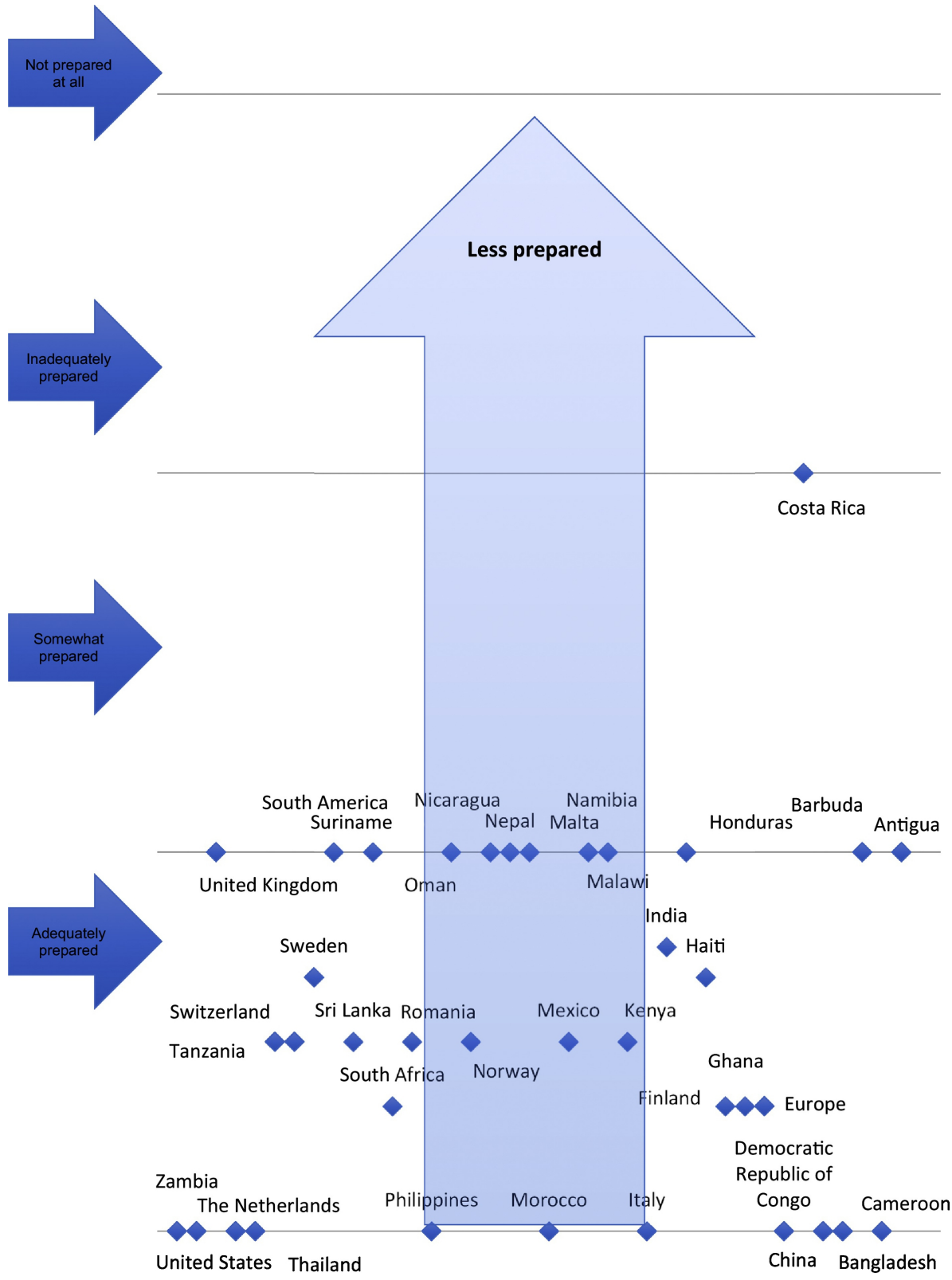




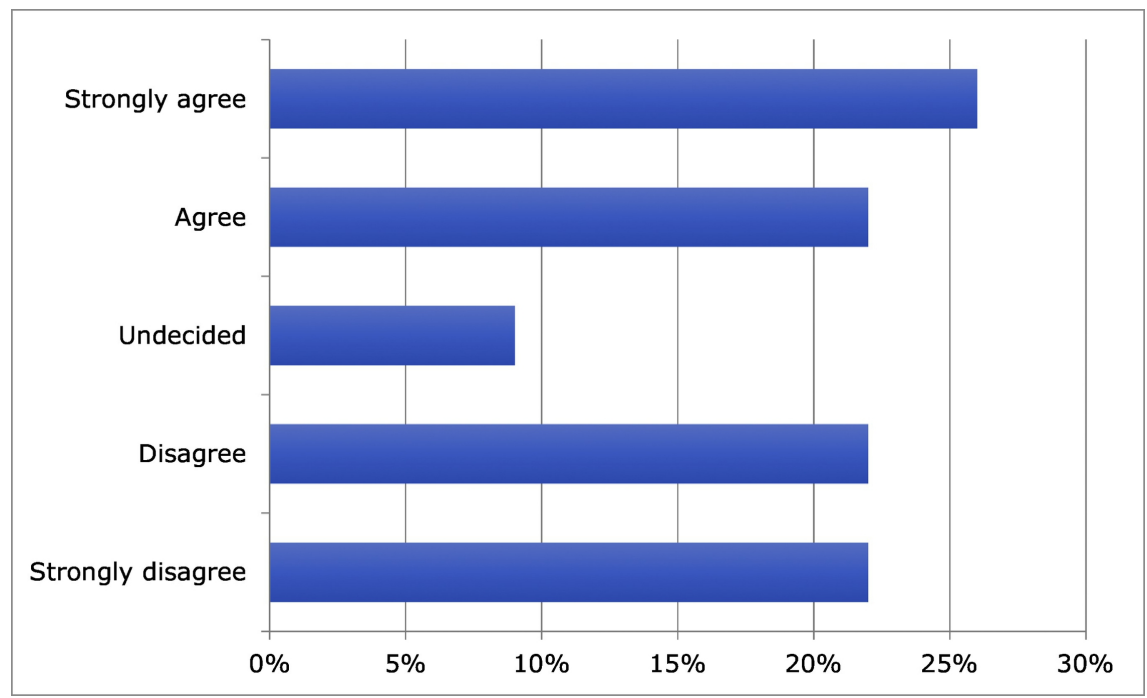

Figure 6 


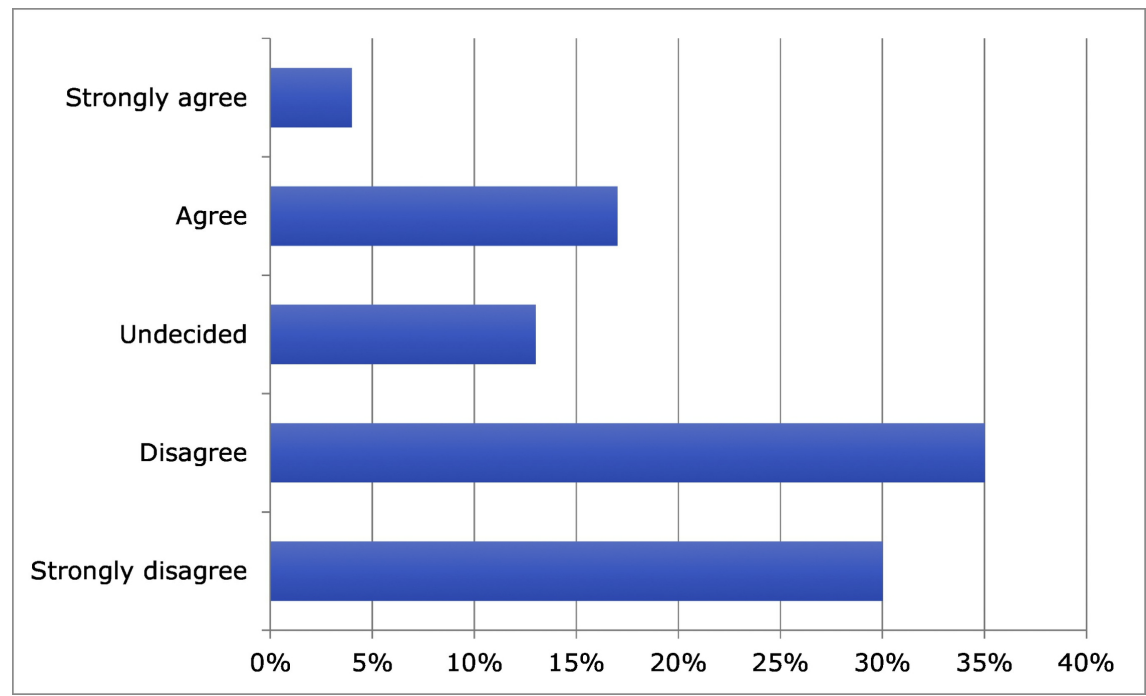

Figure 7 


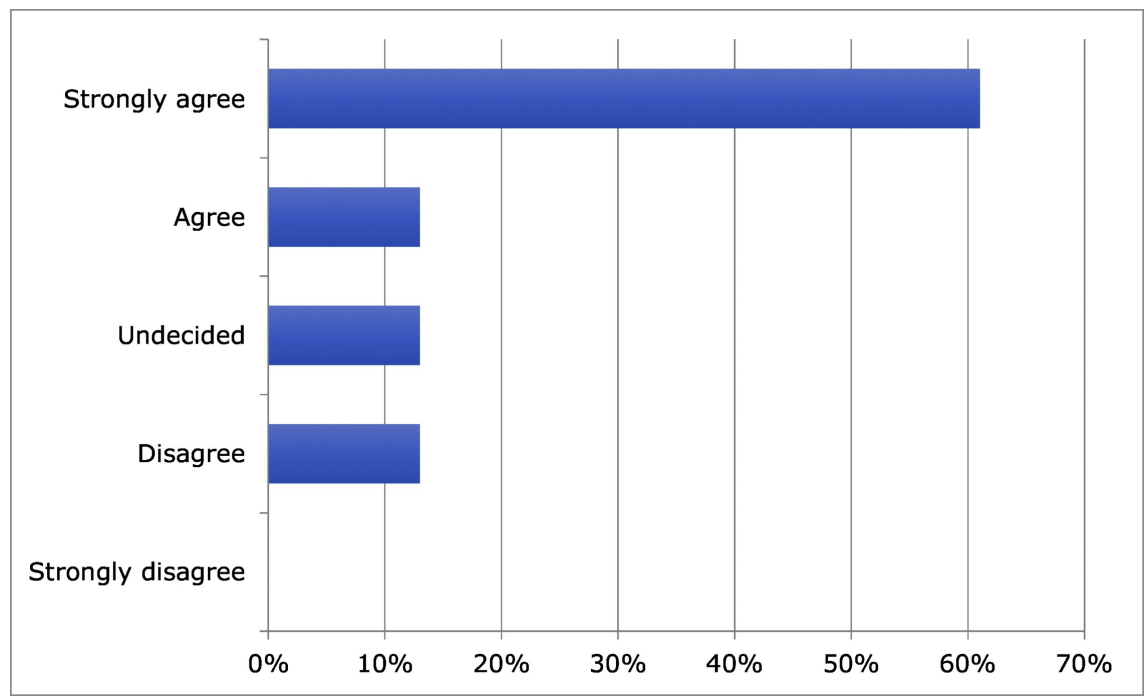

Figure 8 
Acquire country specific knowledge such as culture, history, religion, economy, healthcare structure

An attitude of flexibility/resilience when faced with unexpected events

Anticipate what they will see, hear, smell, encounter that is different than the students' home

Learn common phrases if not familiar with host language

Prepared for their return home, i.e. opportunity to debrief

Understand that they will cannot be $100 \%$ prepared

Understand the underlying public health issues that affect a community

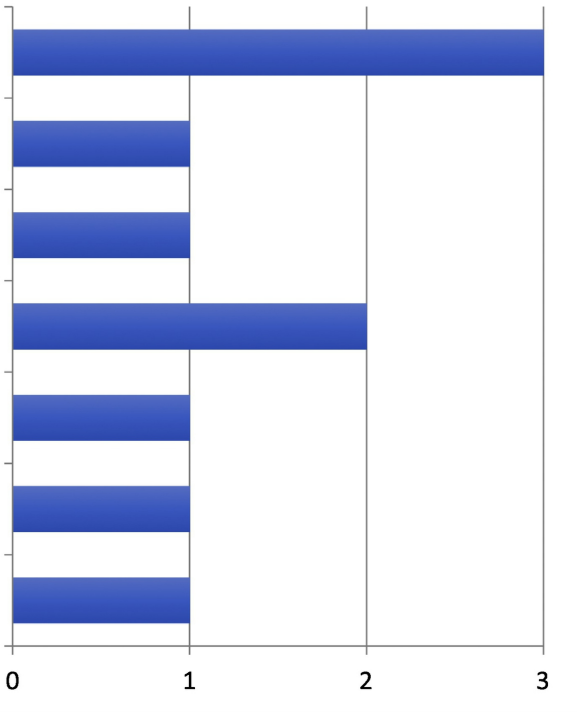

Figure 9 
Round 1

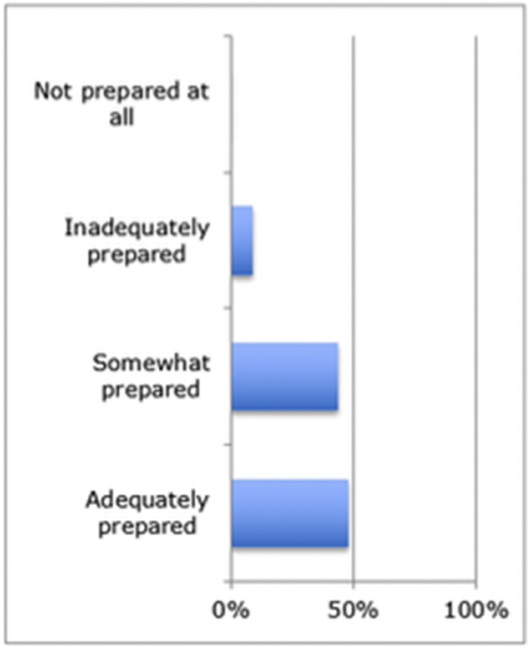

Round 1|

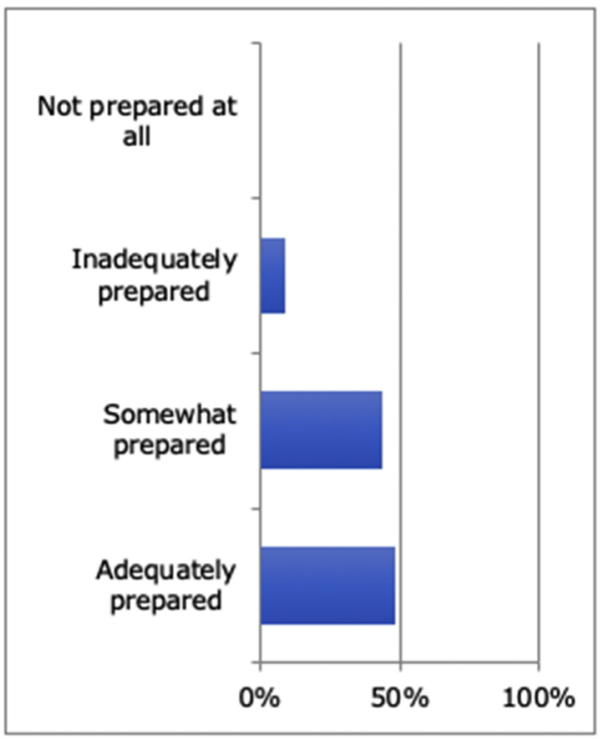

Round 2

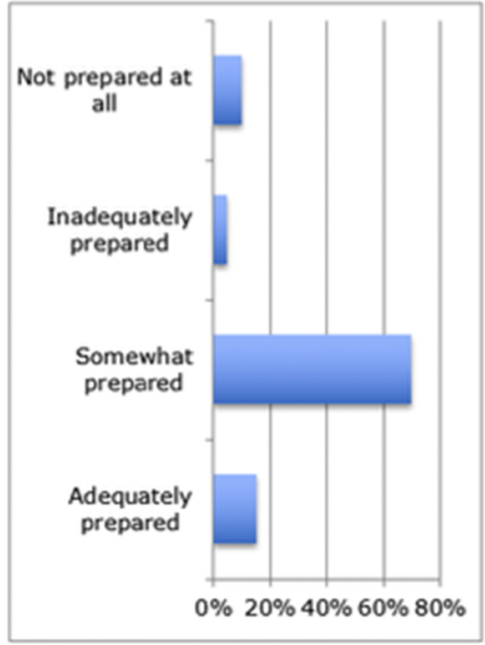

\section{Round 2}

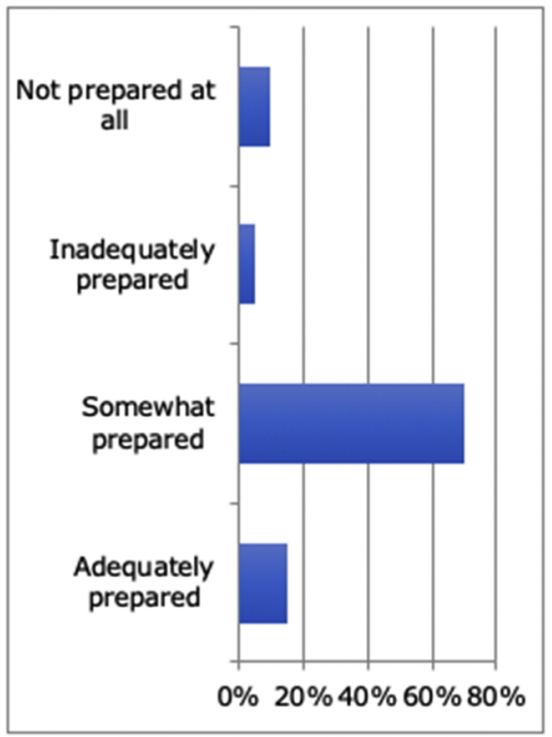


Round 1

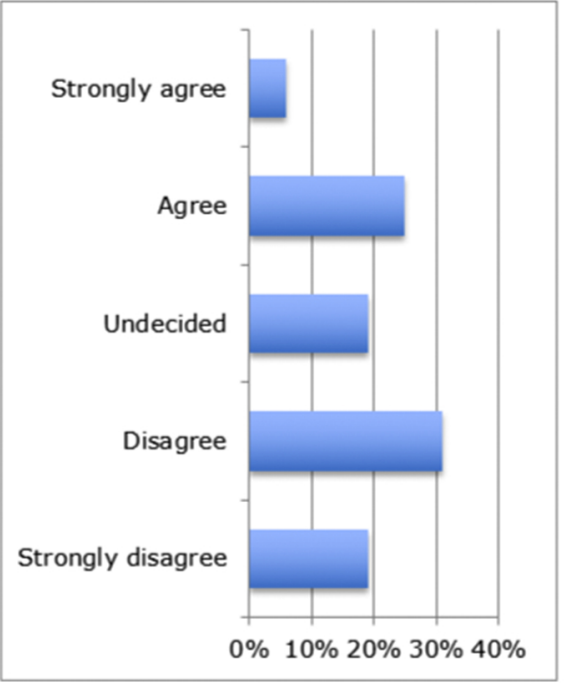

Round 2

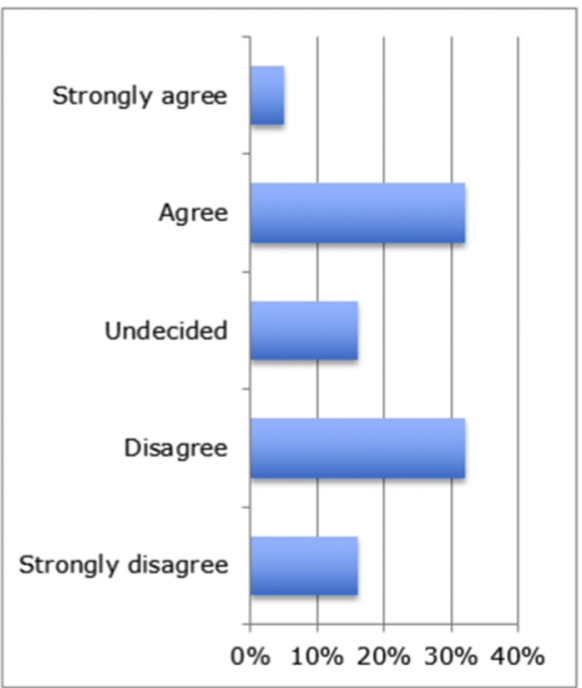

Figure 11 